\title{
In Vitro Multi-Species Oral Biofilms Grown in Presence of H2O2 Production-Affecting Substrates Show Health-Associated Alterations in Composition, Metabolism and Virulence.
}

\author{
Tim Verspecht \\ University of Leuven (KU Leuven) \\ Dorien Vermeulen \\ University of Leuven (KU Leuven) \\ Wannes Van Holm \\ University of Leuven (KU Leuven) \\ Naiera Zayed \\ University of Leuven (KU Leuven) \\ Kristel Bernaerts \\ University of Leuven (KU Leuven) \\ Nico Boon \\ Ghent University (UGent) \\ Wim Teughels ( $\nabla$ wim.teughels@med.kuleuven.be) \\ University of Leuven (KU Leuven)
}

\section{Research Article}

Keywords: therapeutic strategy, Biofilms, virulence genes, periodontal pathogens

Posted Date: June 2nd, 2021

DOI: https://doi.org/10.21203/rs.3.rs-568968/v1

License: (c) (i) This work is licensed under a Creative Commons Attribution 4.0 International License.

Read Full License 
1 In vitro multi-species oral biofilms grown in presence of $\mathrm{H}_{2} \mathrm{O}_{2}$ production-affecting 2 substrates show health-associated alterations in composition, metabolism and 3 virulence.

4

Tim Verspecht ${ }^{1,2}$, Dorien Vermeulen ${ }^{1}$, Wannes Van Holm ${ }^{1,2}$, Naiera Zayed ${ }^{1,2,3}$, Kristel

7

8 3000 Leuven, Belgium.

${ }^{2}$ Center for Microbial Ecology and Technology (CMET), Ghent University (UGent), Coupure Links 653, 9000 Gent, Belgium.

$12{ }^{3}$ Faculty of Pharmacy, Menoufia University, Egypt.

$13{ }^{4}$ Bio- and Chemical Systems Technology, Reactor Engineering and Safety, Department of 14 Chemical Engineering, University of Leuven (KU Leuven), Leuven Chem\&Tech, Celestijnenlaan 200F (bus 2424), 3001 Leuven, Belgium.

${ }^{5}$ Dentistry, University Hospitals Leuven, Kapucijnenvoer 33, 3000 Leuven, Belgium.

E-mail addresses authors: tim.verspecht@kuleuven.be, dorien vermeulen@hotmail.com, wannes.vanholm@kuleuven.be, naiera.zayed@kuleuven.be, kristel.bernaerts@kuleuven.be, nico.boon@ugent.be, wim.teughels@med.kuleuven.be

* Corresponding author: Wim Teughels, KU Leuven, Department of Oral Health Sciences, 23 Kapucijnenvoer 33, 3000 Leuven, Belgium. Phone: +32 (0)16 332 505, fax: +32 (0)16 332484 .

E-mail: wim.teughels@med.kuleuven.be 
Modulation of the commensal oral microbiota is a promising preventive or therapeutic strategy for oral health and can for instance be achieved by increasing the abundance and/or activity of certain species. This study evaluated whether 10 selected substrates could modulate in vitro multi-species oral biofilms towards a more health-associated state. These substrates were chosen based on the possibility that they could stimulate $\mathrm{H}_{2} \mathrm{O}_{2}$ production by certain commensal species and/or increase their abundance, as previously reported or as hypothesized based on known bacterial $\mathrm{H}_{2} \mathrm{O}_{2}$ pathways. Biofilms grown in presence of the substrates at a clinically relevant concentration of $1 \%(\mathrm{w} / \mathrm{v})$ often showed increased abundances of commensal species and decreased abundances of periodontal pathogens. Furthermore, most biofilms also showed an altered metabolic profile. Effects on the expression of a selection of virulence genes were substrate-dependent, but often a decreased expression of certain genes could be observed. In conclusion, this study found that a selection of substrates chosen for their hypothesized beneficial effects on the commensal oral microbiota were able to modulate in vitro multi-species oral biofilms towards a more health-associated state. These modulatory effects were found to be substrate-dependent. 


\section{INTRODUCTION}

The health status of the oral cavity is determined by a variety of external factors such as oral hygiene, diet and lifestyle ${ }^{1,2}$. Simultaneously, also the intrinsic characteristics of an individual such as age, genetic predisposition and systemic diseases are known to strongly influence one's predisposition to develop oral illnesses such as periodontal disease ${ }^{3-5}$. Eventually, the oral health status will be determined by the presence or absence of a complex, calibrated interplay between the host, its environment and its commensal oral microbiota ${ }^{6}$. Knowledge on the latter has increased exponentially over the past decades, leading to the understanding that despite the existence of inter- and intra-individual variability, each person possesses a socalled 'core oral microbiome' that plays a crucial role in maintaining the homeostatic, symbiotic relationship between the oral microbiota and its host ${ }^{7-9}$.

In oral health, an individual's oral microbiota mainly consists of a few hundred bacterial species that often organize into robust, highly specialized oral biofilms (dental plaque) ${ }^{6,8,9}$. Within these biofilms, an optimal microenvironment allows oral bacteria to flourish while they are sheltered from external aggressors and stress but where they are also in close contact with each other ${ }^{10,11}$. As a result, complex inter- and intra-species interactions occur that help shape the homeostatic balances. These interactions are diverse and mediated through for instance metabolic cross-feeding and the production of substances (e.g. hydrogen peroxide $\left(\mathrm{H}_{2} \mathrm{O}_{2}\right)$ ) that (in)directly affect the function and survival of nearby species ${ }^{12-14}$. In this way, the commensal oral microbiota can deal with potentially disease-provoking disruptions while maintaining its core composition and functions ${ }^{15}$. However, once these disruptions surpass a certain threshold and/or when the function of the commensal oral microbiota is impaired, an imbalanced relationship between host and microbiota or within the microbiota eventually leads to dysbiosis and the onset and progression of oral diseases ${ }^{6,15,16}$. Up until today, prevention and treatment of oral diseases are mainly accomplished by mechanical strategies (i.e. plaque removal) in combination with adjunctive antimicrobial therapy (i.e. antibiotics or antiseptics) ${ }^{17-21}$. However, these approaches also come with certain disadvantages, such as the often aspecific removal and killing of both pathogenic and 
commensal species. Furthermore, the widespread use of antimicrobials makes that the risk for adaptation or resistance development could be lurking around the corner ${ }^{19,22,23}$. Therefore, the focus shifted towards the modulation of the commensal oral microbiota to prevent disruption of oral health-associated homeostatic relationships, or to restore them. Probiotics for oral health are an example of such a 'pro-microbial approach', where live microorganisms are administered that eventually provide a health benefit to the host, for instance by inhibiting pathogens through the production of $\mathrm{H}_{2} \mathrm{O}_{2}$ or acids ${ }^{24,25}$. Nowadays, probiotics for oral health are being successfully used in clinical practice ${ }^{26,27}$. Another example is the use of prebiotics, where substrates are administered that are selectively used by endogenous microorganisms resulting in a health benefit, accomplished by for instance increasing the abundance of commensal species or stimulating their metabolism or health-associated functions ${ }^{28}$. The potential of prebiotics for oral health has mainly been demonstrated in vitro ${ }^{29-31}$, but also some in vivo studies were conducted, making it a rapidly evolving research field ${ }^{32,33}$. Lastly, several other strategies to modulate the commensal oral microbiota are under investigation, such as the use of synbiotics (combination of pro- and prebiotics) or the exploitation of specific functions like increasing the abundance of $\mathrm{H}_{2} \mathrm{O}_{2}$ producers or boosting their $\mathrm{H}_{2} \mathrm{O}_{2}$ production $^{14,34,35}$

The current study hypothesized that certain substrates could modulate in vitro multi-species oral biofilms towards a more health-associated state. These substrates were selected based on the possibility that they could positively influence $\mathrm{H}_{2} \mathrm{O}_{2}$ production by certain oral species or increase their abundance. For some substrates, this was described in literature, whereas for others this was hypothesized based on known bacterial $\mathrm{H}_{2} \mathrm{O}_{2}$ production pathways. More specifically, arabinose, sorbitol and saccharin have been shown to stimulate $\mathrm{H}_{2} \mathrm{O}_{2}$ production by $S$. oralis and $S$. sanguinis ${ }^{36}$, whereas pyruvate and lactate are two substrates with a central role in the two major oral streptococcal $\mathrm{H}_{2} \mathrm{O}_{2}$ production pathways ${ }^{14,37,38}$. Furthermore, it is known that lactic acid might serve as a substrate for certain streptococcal species resulting in the production of $\mathrm{H}_{2} \mathrm{O}_{2}{ }^{38,39}$. Potassium acetate was shown to slightly affect $\mathrm{H}_{2} \mathrm{O}_{2}$ production by S. gordoni $i^{40}$, which led to the hypothesis this could also be the case for sodium acetate. Finally, 
97 the conversion of fumarate to succinate is known to yield $\mathrm{H}_{2} \mathrm{O}_{2}$ as a by-product, and succinate

98 can in turn be re-converted to fumarate ${ }^{41}$, which led to the inclusion of these two substrates.

99 Given the complex nature of multi-species biofilms and the fact that accurate $\mathrm{H}_{2} \mathrm{O}_{2}$

100 measurement within oral biofilms is very difficult to accomplish, this study followed a top-down

101 approach and the focus lied only on evaluating the effects the substrates have on in vitro multi-

102 species oral biofilms. Therefore, this study aimed to investigate whether the selected

103 substrates have beneficial modulatory effects on the composition, metabolic profile and

104 virulence of in vitro multi-species oral biofilms grown in presence of these substrates at a

105 clinically relevant concentration. 
The effects of each substrate on the absolute and relative abundances of the different species were evaluated to determine their impact on biofilm composition. Most substrates were found to have a significant influence on absolute bacterial numbers in terms of increases/decreases in comparison with the control condition (Fig. 1, Supplementary Table S1). Biofilm formation in presence of sodium L-lactate resulted in a $1.5 \log (\mathrm{Geq} / \mathrm{mL})$ increase in $S$. oralis numbers and a $0.6 \log (\mathrm{Geq} / \mathrm{mL})$ decrease in $P$. gingivalis numbers. For sodium pyruvate, also an increase in $S$. oralis abundance was observed $(+1.5 \log (\mathrm{Geq} / \mathrm{mL}))$, whereas F. nucleatum and P. intermedia abundance decreased (-1.5 and $-0.3 \log (\mathrm{Geq} / \mathrm{mL}))$. Sodium acetate and D-(-)arabinose also yielded an increase in $S$. oralis numbers $(+1.4$ and $+1.5 \log (\mathrm{Geq} / \mathrm{mL}))$, with D(-)-arabinose also decreasing $A$. naeslundii numbers $(-0.3 \log (\mathrm{Geq} / \mathrm{mL}))$. Potassium acetate resulted for $F$. nucleatum in a decrease $(-1.2 \log (\mathrm{Geq} / \mathrm{mL}))$ and in an increase for S. gordonii $(+0.4 \log (\mathrm{Geq} / \mathrm{mL}))$ and S. oralis $(+1.2 \log (\mathrm{Geq} / \mathrm{mL}))$. Biofilms formed in presence of lactic acid and saccharin showed decreased $A$. actinomycetemcomitans $(-0.4$ and $-0.9 \log (\mathrm{Geq} / \mathrm{mL}))$ and F. nucleatum numbers $(-0.8$ and $-1.9 \log (\mathrm{Geq} / \mathrm{mL}))$, with saccharin also resulting in decreased P. intermedia and S. gordonii numbers (-2.6 and $-0.2 \log (\mathrm{Geq} / \mathrm{mL}))$. D-sorbitol led to decreased numbers of $A$. actinomycetemcomitans and $P$. gingivalis $(-0.6$ and $-0.5 \log (\mathrm{Geq} / \mathrm{mL}))$ and increased numbers of $S$. mutans, $S$. mitis and $S$. sanguinis $(+1.4,+0.2$ and $+1.4 \log (\mathrm{Geq} / \mathrm{mL}))$. Biofilms grown in presence of sodium fumarate showed decreased $F$. nucleatum and $S$. oralis numbers $(-1.6$ and $-0.4 \log (\mathrm{Geq} / \mathrm{mL}))$. Sodium succinate did not result in significant changes in absolute bacterial abundances.

Most substrates also significantly affected the relative abundances of commensal species, periodontal and cariogenic pathogens (Table 1). For one set of substrates, control biofilms harboured $21.8 \pm 3.0 \%$ commensal species, $77.8 \pm 3.0 \%$ periopathogens and $0.4 \pm 0.1 \%$

131 cariogenic pathogens. (Table 1). D-sorbitol, saccharin, lactic acid and sodium fumarate altered 132 the proportion of commensals to $55.2 \pm 14.8,82.6 \pm 8.6,65.9 \pm 7.4$ and $74.5 \pm 7.5 \%$, respectively, while decreasing the abundance of periopathogens to $43.6 \pm 15.0,13.2 \pm 6.3,33.3 \pm 7.2$ and 
$13424.2 \pm 7.2 \%$, respectively. Saccharin also increased cariogenic pathogens abundance $135(4.2 \pm 2.3 \%)$. For the other set of substrates, the control biofilms consisted of $31.7 \pm 9.3 \%$ commensal species, $68.3 \pm 9.3 \%$ periopathogens and $0.1 \pm 0.0$ cariogenic pathogens (Table 1 ).

137 Significant shifts in biofilm composition were observed for biofilms grown in presence of sodium 138 L-lactate $(82.9 \pm 7.0 \%$ commensals, $17.0 \pm 7.0 \%$ periopathogens $)$, potassium acetate $139(69.7 \pm 8.6 \%$ commensals, $30.2 \pm 8.6$ periopathogens $)$ and sodium pyruvate $(0.5 \pm 0.2 \%$ 140 cariogenic pathogens).

\section{Metabolic modulation of multi-species biofilms}

143 To investigate the effects of each substrate on the metabolic profiles of the biofilms, levels of 144 organic acids in the biofilm supernatants were determined (Table 2). For one set of substrates, control biofilms consumed $170 \pm 2 \mathrm{mg} / \mathrm{L}$ lactate and produced $94 \pm 103 \mathrm{mg} / \mathrm{L}$ formate, $4312 \pm 119$

$146 \mathrm{mg} / \mathrm{L}$ acetate, $2722 \pm 23 \mathrm{mg} / \mathrm{L}$ propionate and $2498 \pm 121 \mathrm{mg} / \mathrm{L}$ butyrate (Table 2). Biofilm growth 147 in presence of sodium fumarate resulted in significant lactate production $(1490 \pm 717 \mathrm{mg} / \mathrm{L})$, 148 whereas saccharin and sodium succinate increased acetate production $(1549 \pm 90$ and $1493121 \pm 449 \mathrm{mg} / \mathrm{L})$. D-sorbitol, saccharin, lactic acid, sodium succinate and sodium fumarate increased propionate production $(6726 \pm 96,1735 \pm 37,6166 \pm 93,5345 \pm 54$ and $4557 \pm 177 \mathrm{mg} / \mathrm{L})$ whereas butyrate production was decreased $(1397 \pm 166,280 \pm 25,1312 \pm 358,1308 \pm 510$ and $409 \pm 87 \mathrm{mg} / \mathrm{L})$. For the other set of substrates, control biofilms consumed $194 \pm 0 \mathrm{mg} / \mathrm{L}$ lactate, $226 \pm 7 \mathrm{mg} / \mathrm{L}$ formate, $5104 \pm 105 \mathrm{mg} / \mathrm{L}$ acetate, $3135 \pm 182 \mathrm{mg} / \mathrm{L}$ propionate and $2449 \pm 224 \mathrm{mg} / \mathrm{L}$ butyrate (Table 2). Biofilms grown in presence of sodium L-lactate showed decreased lactate consumption $(104 \pm 2 \mathrm{mg} / \mathrm{L})$, increased acetate and propionate production $(5907 \pm 66$ and $7117 \pm 206 \mathrm{mg} / \mathrm{L})$, and decreased butyrate production (1868 $\pm 117 \mathrm{mg} / \mathrm{L})$. Sodium pyruvate yielded elevated levels of formate, acetate, propionate and butyrate $(921 \pm 74,7817 \pm 41$, $3819 \pm 40$ and $2086 \pm 38 \mathrm{mg} / \mathrm{L})$, whereas potassium acetate and sodium acetate increased acetate production (10624 \pm 14 and $8524 \pm 264 \mathrm{mg} / \mathrm{L})$. 
163 A selection of virulence genes from three periodontal pathogens (A. actinomycetemcomitans, F. nucleatum and $P$. gingivalis) was made of which the expression profiles were analysed to determine the effects of each substrate on multi-species biofilm virulence (Table 3). Noteworthy is that significant changes in virulence gene expression relative to the control condition were only considered to be biologically relevant when there was $>1.5$-fold upregulation or $>2$-fold downregulation and that only such changes were considered. Altogether, as can be seen based on the color scale used in Table 3, more substrate-gene combinations showed at least a tendency towards decreased virulence gene expression than combinations showing at least a tendency towards increased virulence gene expression. For D-sorbitol, lactic acid, sodium fumarate, D-(-)-arabinose, 6/10 genes showed a tendency towards downregulated expression, for sodium succinate and sodium acetate this were $5 / 10$ genes, for saccharin, sodium L-lactate and sodium pyruvate 4/10 genes and for potassium acetate $3 / 10$ genes.

For five substrates, A. actinomycetemcomitans virulence gene expression was found to be downregulated 3.3- to 100-fold (Table 3). D-(+)-sorbitol downregulated apaH, cagE and orf859 expression (3.6-, 100- and 5.9-fold). Lactic acid, sodium fumarate, D-(-)-arabinose and sodium acetate downregulated orf859 expression with 3.3-, 4.0-, 5.9- and 3.4-fold. On the other hand, $p g A$ expression was upregulated for D-sorbitol, saccharin and sodium pyruvate (3.6-, 3.8- and 3.2-fold). For F. nucleatum, hemin receptor gene expression was downregulated 2.3- to 9.1fold for D-sorbitol, lactic acid, potassium acetate and sodium acetate (Table 3). Hemolysin gene expression was upregulated 3.6-fold for saccharin. $A B C$ transporter permease gene expression was downregulated 2.3-fold for D-sorbitol, whereas for saccharin, sodium succinate, sodium fumarate, sodium L-lactate, sodium pyruvate and sodium acetate, 2.3- to 18-fold upregulation was observed. Finally, P. gingivalis fimA expression was downregulated

187 for sodium succinate and sodium lactate (3.3- and 3.6-fold) and upregulated for saccharin and 188 potassium acetate (3.6- and 2.7-fold) (Table 3). The expression of kgp was 25.0-fold downregulated for saccharin and 18.8-fold upregulated for sodium pyruvate, whereas rgpA 
expression was 3.6- to 4.8-fold downregulated for sodium succinate, sodium L-lactate and sodium acetate.

\section{DISCUSSION}

Research on novel preventive and therapeutic interventions for oral health is rapidly evolving, with one of the focuses lying on the modulation of the commensal oral microbiota as a 'pro-microbial' approach. Such modulation can for instance be achieved by increasing the abundance and/or activity of certain species, eventually resulting in a more balanced oral microbiota. This study evaluated whether 10 selected substrates could modulate in vitro multispecies oral biofilms towards a more health-associated microbiological composition, an altered metabolic activity and a decreased virulence gene expression profile. The selection of the evaluated substrates was based on the possibility that they could stimulate $\mathrm{H}_{2} \mathrm{O}_{2}$ production by certain commensal species and/or increase their abundance, which has been described in literature or was hypothesized based on known bacterial $\mathrm{H}_{2} \mathrm{O}_{2}$ pathways. Biofilm growth in presence of the substrates at a clinically relevant concentration of $1 \%(w / v)$ often resulted in a microbiological composition with increased abundances of commensal species and decreased abundances of periodontal pathogens. Furthermore, most substrate conditions also altered the metabolic profiles of these biofilms. The effects on virulence gene expression, based on a selection of 10 important virulence genes of 3 periodontal pathogens, were highly substratedependent, but for several substrates a decreased expression of certain genes could be observed. Altogether, this study provides novel findings on oral biofilm modulation by 10 substrates selected for their possible effects on the activity and/or abundance of certain commensal oral bacteria. To our knowledge, this work is the first one to simultaneously investigate the modulatory effects of these specific substrates on the microbiological composition, metabolic and virulence profiles of complex, in vitro multi-species oral biofilms.

The substrates included in this study were selected based on previous findings in literature and/or their involvement in bacterial $\mathrm{H}_{2} \mathrm{O}_{2}$ production pathways. Arabinose, sorbitol and saccharin have been shown to stimulate $\mathrm{H}_{2} \mathrm{O}_{2}$ production by $S$. oralis and S. sanguinis ${ }^{36}$. 
218 Pyruvate and lactate are two substrates with a central role in the two major oral streptococcal $219 \mathrm{H}_{2} \mathrm{O}_{2}$ production pathways ${ }^{14,37,38}$. Furthermore, it is known that lactic acid might serve as a 220 substrate for certain streptococcal species resulting in the production of $\mathrm{H}_{2} \mathrm{O}_{2}{ }^{38,39}$. Potassium acetate was shown to slightly affect $\mathrm{H}_{2} \mathrm{O}_{2}$ production by $S$. gordoni ${ }^{40}$, which led to the hypothesis this could also be the case for sodium acetate. Finally, the conversion of fumarate to succinate is known to yield $\mathrm{H}_{2} \mathrm{O}_{2}$ as a by-product, and succinate can in turn be re-converted

224 to fumarate ${ }^{41}$. The selected substrates thus have a clear link with $\mathrm{H}_{2} \mathrm{O}_{2}$-producing commensal 225 oral species, but the current study merely focused on the effects of these substrates on multispecies oral biofilms rather than on the potential underlying mechanisms of these effects. The rationale for this is that accurate determination of $\mathrm{H}_{2} \mathrm{O}_{2}$ production within complex oral biofilms has not been achieved yet. Due to diffusion restrictions, the effects of $\mathrm{H}_{2} \mathrm{O}_{2}$ can be very localized and take mainly place within the biofilm ${ }^{42,43}$. Furthermore, determining the effects of the substrates on certain aspects of a complex multi-species community could be considered to be more relevant than merely investigating their mode of action in a simpler setting. Since $\mathrm{H}_{2} \mathrm{O}_{2}$ plays an important role in shaping oral bacterial communities during biofilm development ${ }^{14,43}$, this study evaluated the effect of the presence of the substrates during oral biofilm formation.

Dysbiosis is one of the main hallmarks of oral disease development and is characterized by a decreased prevalence and/or function of commensal species, whereas the 237 opposite is true for (potentially) pathogenic species ${ }^{15,44,45}$. Consequently, modulation of the oral 238 microbiota envisions the achievement of increased abundances of commensals and/or 239 decreased abundances of pathogens. The majority of the substrates tested in this study 240 achieved at least one, and often both, of these goals. This shows potential for these substrates 241 as modulators of oral biofilms, since previous studies on potential prebiotic substrates for oral 242 health reported similar effects on multi-species biofilm composition ${ }^{30,31,33,46}$. The role of species 243 like $A$. actinomycetemcomitans, F. nucleatum, $P$. gingivalis and $P$. intermedia in the initiation 244 and progression of periodontal diseases has been well-characterized ${ }^{11,44,47,48}$. However, some 245 streptococci like S. oralis, S. mitis, S. sanguinis and S. gordonii are well-known $\mathrm{H}_{2} \mathrm{O}_{2}$-producers 
246 that play a role in shaping oral communities during biofilm development, whereas pathobionts

247 like $P$. gingivalis and $P$. intermedia are susceptible to $\mathrm{H}_{2} \mathrm{O}_{2}$-mediated toxicity ${ }^{49}$. For substrates

248 with a compositional effect, changes in abundances were generally observed for one or more

249 of the above-mentioned species. For instance, sodium lactate, sodium pyruvate and potassium

250 acetate all resulted in increased $S$. oralis numbers while simultaneously also a decrease in one

251 or two periodontal pathogens like $P$. gingivalis, $P$. intermedia and $F$. nucleatum was observed.

252 On the other hand, sorbitol was found to increase S. mitis and S. sanguinis numbers while also

253 decreasing $A$. actinomycetemcomitans and $P$. gingivalis numbers. The effects of other

254 substrates like saccharin or lactic acid were generally limited to decreases in periopathogens.

255 However, this does not automatically imply that such substrates have no effects on the activity

256 of commensal species, as saccharin and lactic acid have been shown to increase $\mathrm{H}_{2} \mathrm{O}_{2}$ production by certain oral streptococci ${ }^{36,38,39}$. Altogether, the majority of the substrates tested

258 in this study shifted the biofilm composition towards a more health-associated one. It can be 259 hypothesized that, besides increasing the abundance of certain commensals, this could also 260 be mediated by stimulating the activity of these species.

Insights into the metabolic profile of oral communities can provide valuable information on the role they play in oral health or disease. In periodontal disease, inflammophilic species characterized by asaccharolytic and proteolytic metabolisms are enriched in abundance and show increased activity ${ }^{15,50,51}$. This eventually provides for a reciprocally reinforced feedback loop between inflammation and dysbiosis, allowing such species to thrive and which acts as an important disease driver ${ }^{15}$. Species like Porphyromonas, Prevotella and Fusobacterium are characterized by such metabolic profiles through which peptides and amino acids are converted into organic acids like formate, acetate, propionate and butyrate ${ }^{50,52}$. In this study, it was remarkable that most of the substrate conditions showed decreases in butyrate production. Although butyrate is known to play a protective role in the gut, butyrate production 271 in the oral cavity is known to be associated with periodontal inflammation ${ }^{53-55}$. Therefore, the 272 observed decreased butyrate levels can be considered as a favourable metabolic change. 273 Similar findings on decreased butyrate levels were previously reported in an in vitro study 
274 identifying potential prebiotic substrates for oral health ${ }^{46}$. However, commensal species like

275 Actinomyces and Streptococcus have a saccharolytic metabolism, leading to the production of 276 lactate, acetate and formate ${ }^{52}$. Given that several substrate conditions showed increases in 277 one or two streptococcal species, one would expect to observe an increase in lactate levels, 278 although this was not the case. This can be explained by the complexity of multi-species 279 biofilms, which are characterized by a wide variety of interspecies interactions and metabolic 280 cross-feeding ${ }^{11,52,56-58}$. Lactate produced by streptococci forms a nutritional source for 281 Actinomyces and Veillonella species, which results in the production of formate, acetate and 282 propionate (Veillonella spp.) or acetate (Actinomyces spp. $)^{52,56,57}$. Formate has been shown to 283 have an inverse relationship with the severity of periodontal disease ${ }^{53}$, and in the current study, 284 it was increased in the sodium pyruvate condition. On the other hand, in some studies, it has 285 also been associated with undesired effects on oral epithelial cells in vitro, which is also the case for acetate and propionate ${ }^{59}$. However, given the entanglement of metabolic pathways within complex multi-species oral biofilms, it is difficult to fully interpret the impact of all metabolic shifts observed in this study.

Pathogenic bacteria in dysbiotic oral communities are often characterized by a 290 pronounced virulence that allows them to persist, thrive and contribute to disease progression ${ }^{60,61}$. The virulence genes evaluated in this study were selected based on their wellknown involvement in periodontal disease onset and progression ${ }^{62-67}$. Effects on virulence 293 gene expression were highly dependent on the substrate and pathogenic species under 294 consideration. For instance, downregulated apaH, cagE and orf859 expression in $A$. actinomycetemcomitans was observed for the sorbitol condition. These genes encode virulence factors involved in the invasion of non-phagocytic cells $(a p a H)^{62}$, conjugation, DNA transport and virulence factor secretion $(\mathrm{cag} E)^{66}$ and intracellular survival (orf859) ${ }^{62}$. Orf859 298 expression was also downregulated in several other conditions. Remarkable was the 299 increased $p g A$ expression in the sorbitol, saccharin and sodium pyruvate conditions. $P g A$ 300 encodes a protein involved in the synthesis of a polysaccharide with an important role in 301 aggregation and biofilm formation ${ }^{63}$. Similar observations for $p g A$ expression in modulated oral 
302 biofilms were also previously observed ${ }^{46}$, and this could be explained as a response to external 303 stress, something reported for other Aggregatibacter species ${ }^{68}$. For F. nucleatum, 304 downregulation was often observed for the gene encoding a hemin receptor, which is highly 305 immunogenic and plays an important role in hemin uptake ${ }^{65}$. Apart from sorbitol and lactic acid, 306 most conditions showed upregulated $A B C$ transporter permease gene expression. As its gene 307 product is involved in membrane transport ${ }^{65}$, this could also be a response to the induced 308 environmental changes. For $P$. gingivalis the effects were also diverse. Most substrates led to 309 decreased $\operatorname{rgp} A$ expression, a gingipain gene encoding an arginine-specific cysteine protease 310 involved in several processes such as disturbance of host defense systems and tissue 311 degradation ${ }^{67}$. FimA and $k g p$ expression, encoding a fimbrilin involved in attachment to oral surfaces and a gingipain gene encoding a lysine-specific cysteine protease, respectively ${ }^{67}$, 313 were sometimes downregulated and sometimes upregulated, depending on the substrate. Altogether, the effects of the substrates on the virulence profiles of the biofilms were 315 found to be highly diverse. Nevertheless, it is important to look at the overall effect of the 316 substrates, since oral diseases are caused by the concerted virulence, (metabolic) function 317 and composition of synergistic polymicrobial biofilms ${ }^{6,16}$. From that point of view, most 318 substrates had beneficial modulatory effects on at least one, and often two or all three of these aspects. To conclude, future research should look into some of the limitations and aspects that were not addressed in the current study. For instance, a broader selection of virulence genes could provide further insight into changes in virulence, and also evaluating the effects on the inflammatory potential of the biofilms towards oral cells could be of interest. Furthermore, now the effects of the substrates on a complex multi-species biofilm have been established, the underlying mechanisms of these effects should be investigated. Given the rationale for the selection of the substrates, this should first focus on the influence they might have on streptococcal $\mathrm{H}_{2} \mathrm{O}_{2}$ production. In conclusion, this study found that a selection of substrates chosen for their hypothesized beneficial effects on the abundance and/or activity of commensal oral bacteria were able to modulate in vitro multi-species oral biofilms towards a more healthassociated state. More specifically, biofilms grown in presence of the substrates at a clinically 
relevant concentration often showed a beneficial shift in microbiological composition, an altered metabolic profile and sometimes a decreased virulence, the latter of which was highly dependent on the substrate under consideration.

\section{MATERIALS AND METHODS}

335

\section{Bacterial strains, growth media and culture conditions}

Aggregatibacter actinomycetemcomitans ATCC 43718, Fusobacterium nucleatum ATCC 10953, Porphyromonas gingivalis ATCC 33277 and Prevotella intermedia ATCC 25611 were used as representative periodontal pathogens, Streptococcus mutans ATCC 25175 and Streptococcus sobrinus ATCC 33478 as representative cariogenic pathogens and Actinomyces naeslundii ATCC 51655, Actinomyces viscosus ATCC 15987, Streptococcus gordonii ATCC 49818, Streptococcus mitis ATCC 49456, Streptococcus oralis DSM 20627, Streptococcus sanguinis LMG 14657 and Veillonella parvula DSM 2008 as representative commensal species. Bacteria were grown on blood agar (Oxoid, Ltd, Basingstoke, UK) supplemented with $5 \mu \mathrm{g} / \mathrm{mL}$ hemin, $1 \mu \mathrm{g} / \mathrm{mL}$ menadione (both Sigma-Aldrich Co, St.-Louis, USA) and 5\% sterile horse blood (E\&O Laboratories Ltd, Bonnybridge, Scotland). A. actinomycetemcomitans, S. gordonii, S. mitis, S. mutans, S. oralis, S. sanguinis and S. sobrinus were grown aerobically $\left(37^{\circ} \mathrm{C}, 5 \% \mathrm{CO}_{2}\right)$ whereas $A$. naeslundii, $A$. viscosus, $F$. nucleatum, $P$. gingivalis, $P$. intermedia and $V$. parvula were grown anaerobically $\left(37^{\circ} \mathrm{C}, 80 \%\right.$ $\mathrm{N}_{2}, 10 \% \mathrm{H}_{2}$, and $10 \% \mathrm{CO}_{2}$ ). Single species planktonic cultures were grown in brain hearth infusion (BHI) broth (Difco Laboratories, Detroit, USA) as described previously ${ }^{30}$. Multi-species biofilms were grown in modified $\mathrm{BHI}$ broth $(\mathrm{BHI}-2)^{30}$.

\section{Bioreactor-derived multi-species community}

A 13-species community was established in a bioreactor (Biostat B Twin 1L bioreactor, Sartorius Stedim Biotech $\mathrm{GmbH}$, Goettingen, Germany) under controlled environmental conditions, as described in detail elsewhere ${ }^{30}$.

\section{Substrates}


The substrates used in this study were selected based on the following two criteria: (1) shown in literature to (possibly) stimulate $\mathrm{H}_{2} \mathrm{O}_{2}$ production by a limited number of oral bacterial species; and/or (2) (in)direct involvement in known pathways of oral bacterial $\mathrm{H}_{2} \mathrm{O}_{2}$ production. All substrates were dissolved in $\mathrm{BHI}-2$ without mucin at a concentration of $2 \%(\mathrm{w} / \mathrm{v})$, followed by $\mathrm{pH}$ adjustment to 7.4 and filter sterilization. For the biofilm experiments, one volume of this was supplemented with one volume of sterile BHI-2 with double-concentrated mucin $(2 \mathrm{x})$, yielding sterile $\mathrm{BHI}-2$ solutions (with $1 \times$ mucin) with a final substrate concentration of $1 \%(\mathrm{w} / \mathrm{v})$. Following substrates were selected for this study: D-(-)-arabinose, lactic acid, potassium acetate, saccharin, sodium fumarate, sodium L-lactate, sodium pyruvate, sodium succinate (all Sigma-Aldrich Co, St. Louis, USA), sodium acetate and D-sorbitol (both VWR, Radnor, USA).

\section{Multi-species biofilm formation assays, DNA extraction and quantification}

368 Biofilms were grown horizontally on Calcium Deficient Hydroxyapatite (CAD-HA) disks 369 (Hitemco Medical, Old Bethpage, USA) on the bottom of a 24-well plate in presence of a 370 substrate. Samples from the bioreactor-derived multi-species community were diluted 1:5 in 371 fresh $\mathrm{BHI}-2$ with $2 \times$ mucin, after which $1 \mathrm{~mL}$ was added to each well containing a HA disk. 372 Equal volumes $(1 \mathrm{~mL})$ of $2 \%(\mathrm{w} / \mathrm{v})$ substrate solutions in $\mathrm{BHI}-2$ without mucin were added to the 373 bacterial suspensions (final multi-species community dilution of $1: 10$, final substrate concentration of $1 \%(\mathrm{w} / \mathrm{v})$ in $\mathrm{BHI}-2)$. As a negative control, $\mathrm{BHI}-2$ without substrate

375 supplementation was used. Biofilms were allowed to grow for $48 \mathrm{~h}$ under micro-aerophilic $(6 \%$ $376 \mathrm{O}_{2}, 7 \% \mathrm{CO}_{2}, 7 \% \mathrm{H}_{2}, 80 \% \mathrm{~N}_{2}$ ) conditions (170 rpm, $37^{\circ} \mathrm{C}$ ). All experiments were repeated on 377 three different days. After $48 \mathrm{~h}$, biofilms were gently washed with phosphate buffered saline 378 (PBS, pH 7.4) to detach non-adherent cells, after which remaining biofilms were disrupted by 379 trypsinization and bacterial cells were harvested as described before ${ }^{30}$. DNA from only living 380 bacteria was extracted using a previously described propidium monoazide (PMA) treatment ${ }^{30}$.

381 Bacterial numbers were determined using a quantitative polymerase chain reaction (qPCR) 382 assay as described by Slomka et al. ${ }^{30}$, whereas species-specific primers and probes were 383 listed by Herrero et al. ${ }^{69}$.

\section{Organic acid analysis of multi-species biofilm supernatants}


385 Concentrations of lactate, acetate, formate, propionate and butyrate in the filter sterilized 386 supernatant of the multi-species biofilm assays were determined with a 761 Compact lon 387 Chromatograph (Metrohm, Switzerland) with a Metrosep Organic acids 250/7.8 column and a 388 Metrosep Organic acids Guard/4.6 guard column, with the eluent consisting of $1 \mathrm{mM} \mathrm{H}_{2} \mathrm{SO}_{4}$ at 389 a flow rate of $0.8 \mathrm{~mL} \mathrm{~min}^{-1}$. Organic acid production/consumption was calculated as the organic acid concentrations detected in the filter sterilized supernatants, minus the concentrations of 391 those organic acids detected in sterile BHI-2 with or without supplemented substrate.

\section{$392 \quad$ RNA extraction and virulence gene expression analysis}

393 Biofilm-coated disks were dip-rinsed in PBS ( $\mathrm{pH}$ 7.4) to remove unattached cells, followed by bacterial RNA extraction as described previously ${ }^{60}$. Briefly, RNA was obtained through a mechanical disruption and acid phenol-chloroform extraction as described by Vandecasteele et al. ${ }^{34}$ in combination with the RNeasy Mini Kit (Qiagen, Hilden, Germany) according to the manufacturer's protocol. After quality and integrity assessment, a concentration-dependent normalization of all RNA samples was performed, followed by conversion of RNA to complementary DNA (cDNA), all as described previously ${ }^{60}$. Expression of bacterial virulence genes was analysed through SYBR RT-qPCR and normalized for bacterial housekeeping gene (species-specific 16S rRNA or other genes) expression. Reaction mixtures were prepared and assay conditions were performed as described by Herrero et al. ${ }^{60}$. Specific sequences of each primer pair can be found elsewhere ${ }^{60}$. Data were determined as a function of the threshold

404 cycle (CT) values and relative virulence gene expression was calculated according to the $405 \Delta \Delta C T$ method $\left(2^{-(\Delta C T e x p-\Delta C T c o n t r o l)}\right)$.

\section{Statistical analysis}

407 Statistical analysis was done using GraphPad Prism v.7.04 for Windows (GraphPad Software, 408 La Jolla, USA). Normality of the residuals was assessed through a Shapiro-Wilk test and a normal quantile plot. For most experiments, comparisons with the control were made and

410 statistically significant differences $(P<0.05)$ were determined through a one-way ANOVA 411 (confidence level of 95\%) followed by Dunnett's correction for simultaneous hypothesis testing. 412 Changes in absolute bacterial abundances expressed as the difference between the value of 
413 the control condition and the value of the substrate condition were analysed through a two-

414 tailed, one sample t test to detect differences significantly different from 0 (no difference

415 between control condition and substrate condition).

\section{DATA AVAILABILITY}

418 The authors declare that all data supporting the findings of this study are available within the paper and its supplementary information files.

\section{REFERENCES}

4221 Marsh, P. D. In Sickness and in Health-What Does the Oral Microbiome Mean to Us?

$423 \quad$ An Ecological Perspective. Adv Dent Res 29, 60-65, doi:10.1177/0022034517735295 (2018).

2 van der Weijden, F. \& Slot, D. E. Oral hygiene in the prevention of periodontal diseases: the evidence. Periodontol 2000 55, 104-123, doi:10.1111/j.1600-0757.2009.00337.x (2011).

3 Genco, R. J. Current view of risk factors for periodontal diseases. J Periodontol 67, 1041-1049, doi:10.1902/jop.1996.67.10.1041 (1996).

4 Cullinan, M. P. \& Seymour, G. J. Periodontal disease and systemic illness: will the evidence ever be enough? Periodontol 2000 62, 271-286, doi:10.1111/prd.12007 (2013).

5 da Silva, M. K. et al. Genetic Factors and the Risk of Periodontitis Development: Findings from a Systematic Review Composed of 13 Studies of Meta-Analysis with 71,531 Participants. Int J Dent 2017, 1914073, doi:10.1155/2017/1914073 (2017).

6 Lamont, R. J., Koo, H. \& Hajishengallis, G. The oral microbiota: dynamic communities and host interactions. Nature Reviews Microbiology 16, 745-759, doi:10.1038/s41579018-0089-x (2018).

7 Sato, Y. et al. Inter-Individual Differences in the Oral Bacteriome Are Greater than IntraDay Fluctuations in Individuals. PLoS One 10, e0131607, doi:10.1371/journal.pone.0131607 (2015).

8 Zaura, E., Keijser, B. J., Huse, S. M. \& Crielaard, W. Defining the healthy "core microbiome" of oral microbial communities. Bmc Microbiol 9, 259, doi:10.1186/14712180-9-259 (2009).

9 Aas, J. A., Paster, B. J., Stokes, L. N., Olsen, I. \& Dewhirst, F. E. Defining the normal bacterial flora of the oral cavity. $J$ Clin Microbiol 43, 5721-5732, doi:10.1128/JCM.43.11.5721-5732.2005 (2005).

10 Marsh, P. D. Microbiology of dental plaque biofilms and their role in oral health and caries. Dent Clin North Am 54, 441-454, doi:10.1016/j.cden.2010.03.002 (2010).

11 Bowen, W. H., Burne, R. A., Wu, H. \& Koo, H. Oral Biofilms: Pathogens, Matrix, and Polymicrobial Interactions in Microenvironments. Trends Microbiol 26, 229-242, doi:10.1016/j.tim.2017.09.008 (2018).

12 Kolenbrander, P. E. et al. Bacterial interactions and successions during plaque development. Periodontol 2000 42, 47-79, doi:10.1111/j.1600-0757.2006.00187.x (2006).

13 Kuramitsu, H. K., He, X., Lux, R., Anderson, M. H. \& Shi, W. Interspecies interactions within oral microbial communities. Microbiol Mol Biol Rev 71, 653-670, doi:10.1128/MMBR.00024-07 (2007). 
Redanz, S. et al. Live and let die: Hydrogen peroxide production by the commensal

460

461

462

463

464

465

466

467

468

469

470

471

472

473

474

475

476

477

478

479

480

481

482

483

484

485

486

487

488

489

490

491

492

493

494

495

496

497

498

499

500

501

502

503

504

505

506

507

508

509

510

511 flora and its role in maintaining a symbiotic microbiome. Molecular Oral Microbiology 33, 337-352, doi:10.1111/omi.12231 (2018).

15 Rosier, B. T., Marsh, P. D. \& Mira, A. Resilience of the Oral Microbiota in Health: Mechanisms That Prevent Dysbiosis. Journal of Dental Research 97, 371-380, doi:10.1177/0022034517742139 (2018).

16 Lamont, R. J. \& Hajishengallis, G. Polymicrobial synergy and dysbiosis in inflammatory disease. Trends Mol Med 21, 172-183, doi:10.1016/j.molmed.2014.11.004 (2015).

17 Berchier, C. E., Slot, D. E., Haps, S. \& Van der Weijden, G. A. The efficacy of dental floss in addition to a toothbrush on plaque and parameters of gingival inflammation: a systematic review. Int J Dent Hyg 6, 265-279, doi:10.1111/j.1601-5037.2008.00336.x (2008).

18 van der Weijden, G. A. \& Hioe, K. P. A systematic review of the effectiveness of selfperformed mechanical plaque removal in adults with gingivitis using a manual toothbrush. J Clin Periodontol 32 Suppl 6, 214-228, doi:10.1111/j.1600051X.2005.00795.x (2005).

19 Marsh, P. D. Controlling the oral biofilm with antimicrobials. J Dent 38 Suppl 1, S1115, doi:10.1016/S0300-5712(10)70005-1 (2010).

20 Feres, M., Figueiredo, L. C., Soares, G. M. \& Faveri, M. Systemic antibiotics in the treatment of periodontitis. Periodontol 2000 67, 131-186, doi:10.1111/prd.12075 (2015).

21 Garcia-Gargallo, M. et al. Evaluation of new chlorhexidine- and cetylpyridinium chloride-based mouthrinse formulations adjunctive to scaling and root planing: pilot study. Int J Dent Hyg 15, 269-279, doi:10.1111/idh.12254 (2017).

22 Verspecht, T. et al. Development of antiseptic adaptation and cross-adapatation in selected oral pathogens in vitro. Sci Rep-Uk 9, doi:10.1038/s41598-019-44822-y (2019).

23 Chatzigiannidou, I., Teughels, W., Van de Wiele, T. \& Boon, N. Oral biofilms exposure to chlorhexidine results in altered microbial composition and metabolic profile. NPJ Biofilms Microbiomes 6, 13, doi:10.1038/s41522-020-0124-3 (2020).

24 Hill, C. et al. Expert consensus document. The International Scientific Association for Probiotics and Prebiotics consensus statement on the scope and appropriate use of the term probiotic. Nat Rev Gastroenterol Hepatol 11, 506-514, doi:10.1038/nrgastro.2014.66 (2014).

25 Marco, M. L., Pavan, S. \& Kleerebezem, M. Towards understanding molecular modes of probiotic action. Curr Opin Biotechnol 17, 204-210, doi:10.1016/j.copbio.2006.02.005 (2006).

26 Martin-Cabezas, R., Davideau, J. L., Tenenbaum, H. \& Huck, O. Clinical efficacy of probiotics as an adjunctive therapy to non-surgical periodontal treatment of chronic periodontitis: a systematic review and meta-analysis. J Clin Periodontol 43, 520-530, doi:10.1111/jcpe.12545 (2016).

27 Shimauchi, H. et al. Improvement of periodontal condition by probiotics with Lactobacillus salivarius WB21: a randomized, double-blind, placebo-controlled study. J Clin Periodontol 35, 897-905, doi:10.1111/j.1600-051X.2008.01306.x (2008).

28 Gibson, G. R. et al. Expert consensus document: The International Scientific Association for Probiotics and Prebiotics (ISAPP) consensus statement on the definition and scope of prebiotics. Nature Reviews Gastroenterology \& Hepatology 14, 491-502, doi:10.1038/nrgastro.2017.75 (2017).

29 Slomka, V. et al. Nutritional stimulation of commensal oral bacteria suppresses pathogens: the prebiotic concept. Journal of Clinical Periodontology 44, 344-352, doi:10.1111/jcpe.12700 (2017).

30 Slomka, V. et al. Oral prebiotics and the influence of environmental conditions in vitro. Journal of Periodontology 89, 708-717, doi:10.1002/jper.17-0437 (2018). 
Rosier, B. T., Buetas, E., Moya-Gonzalvez, E. M., Artacho, A. \& Mira, A. Nitrate as a potential prebiotic for the oral microbiome. Sci Rep 10, 12895, doi:10.1038/s41598020-69931-x (2020). Jockel-Schneider, Y. et al. Stimulation of the nitrate-nitrite-NO-metabolism by repeated lettuce juice consumption decreases gingival inflammation in periodontal recall patients: a randomized, double-blinded, placebo-controlled clinical trial. J Clin Periodontol 43, 603-608, doi:10.1111/jcpe.12542 (2016).

33 Koopman, J. E. et al. Changes in the oral ecosystem induced by the use of $8 \%$ arginine toothpaste. Arch Oral Biol 73, 79-87, doi:10.1016/j.archoralbio.2016.09.008 (2017).

34 Bijle, M. N., Neelakantan, P., Ekambaram, M., Lo, E. C. M. \& Yiu, C. K. Y. Effect of a novel synbiotic on Streptococcus mutans. Sci Rep 10, 7951, doi:10.1038/s41598-02064956-8 (2020).

35 Cheng, X. et al. Magnesium-Dependent Promotion of H2O2 Production Increases Ecological Competitiveness of Oral Commensal Streptococci. J Dent Res 99, 847-854, doi:10.1177/0022034520912181 (2020).

36 Garcia-Mendoza, A., Liebana, J., Castillo, A. M., de la Higuera, A. \& Piedrola, G. Evaluation of the capacity of oral streptococci to produce hydrogen peroxide. $J$ Med Microbiol 39, 434-439, doi:10.1099/00222615-39-6-434 (1993).

37 Carlsson, J., Edlund, M. B. \& Lundmark, S. K. Characteristics of a hydrogen peroxideforming pyruvate oxidase from Streptococcus sanguis. Oral Microbiol Immunol 2, 1520, doi:10.1111/j.1399-302x.1987.tb00264.x (1987).

38 Liu, L., Tong, H. \& Dong, X. Function of the pyruvate oxidase-lactate oxidase cascade in interspecies competition between Streptococcus oligofermentans and Streptococcus mutans. Appl Environ Microbiol 78, 2120-2127, doi:10.1128/AEM.07539-11 (2012).

39 Tong, H. et al. Streptococcus oligofermentans inhibits Streptococcus mutans through conversion of lactic acid into inhibitory H2O2: a possible counteroffensive strategy for interspecies competition. Mol Microbiol 63, 872-880, doi:10.1111/j.13652958.2006.05546.x (2007).

\section{1 peroxide formation by Streptococcus gordonili Infect Immun 67, 6558-6564 (1999).}

41 Messner, K. R. \& Imlay, J. A. Mechanism of superoxide and hydrogen peroxide formation by fumarate reductase, succinate dehydrogenase, and aspartate oxidase. $J$ Biol Chem 277, 42563-42571, doi:10.1074/jbc.M204958200 (2002).

42 Liu, X. et al. Real-time mapping of a hydrogen peroxide concentration profile across a polymicrobial bacterial biofilm using scanning electrochemical microscopy. Proc Natl Acad Sci U S A 108, 2668-2673, doi:10.1073/pnas.1018391108 (2011).

43 Zhu, L. \& Kreth, J. The role of hydrogen peroxide in environmental adaptation of oral microbial communities. Oxid Med Cell Longev 2012, 717843, doi:10.1155/2012/717843 (2012).

44 Hajishengallis, G. \& Lamont, R. J. Beyond the red complex and into more complexity: the polymicrobial synergy and dysbiosis (PSD) model of periodontal disease etiology. Mol Oral Microbiol 27, 409-419, doi:10.1111/j.2041-1014.2012.00663.x (2012).

45 Diaz, P. I., Hoare, A. \& Hong, B. Y. Subgingival Microbiome Shifts and Community Dynamics in Periodontal Diseases. J Calif Dent Assoc 44, 421-435 (2016).

46 Verspecht, T. et al. Potential prebiotic substrates modulate composition, metabolism, virulence and inflammatory potential of an in vitro multi-species oral biofilm. J Oral Microbiol 13, 1910462, doi:10.1080/20002297.2021.1910462 (2021).

47 Kumar, P. S., Griffen, A. L., Moeschberger, M. L. \& Leys, E. J. Identification of candidate periodontal pathogens and beneficial species by quantitative $16 \mathrm{~S}$ clonal analysis. J Clin Microbiol 43, 3944-3955, doi:10.1128/JCM.43.8.3944-3955.2005 (2005).

48 Frias-Lopez, J. \& Duran-Pinedo, A. Effect of periodontal pathogens on the metatranscriptome of a healthy multispecies biofilm model. J Bacteriol 194, 2082-2095, doi:10.1128/JB.06328-11 (2012). 
Herrero, E. R. et al. Antimicrobial effects of commensal oral species are regulated by environmental factors. Journal of Dentistry 47, 23-33, doi:10.1016/j.jdent.2016.02.007 (2016).

568

569

570

571

572

573

574

575

576

577

578

579

580

581

582

583

584

585

586

587

588

589

590

591

592

593

594

595

596

597

598

599

600

601

602

603

604

605

606

607

608

609

610

611

612

613

614

615

616

617

618

Takahashi, N. Microbial ecosystem in the oral cavity: Metabolic diversity in an ecological niche and its relationship with oral diseases. International Congress Series 1284, 103-112, doi:https://doi.org/10.1016/j.ics.2005.06.071 (2005).

51 Hajishengallis, G. The inflammophilic character of the periodontitis-associated microbiota. Mol Oral Microbiol 29, 248-257, doi:10.1111/omi.12065 (2014).

52 Takahashi, N. Oral Microbiome Metabolism: From "Who Are They?" to "What Are They Doing?". J Dent Res 94, 1628-1637, doi:10.1177/0022034515606045 (2015).

53 Qiqiang, L., Huanxin, M. \& Xuejun, G. Longitudinal study of volatile fatty acids in the gingival crevicular fluid of patients with periodontitis before and after nonsurgical therapy. J Periodontal Res 47, 740-749, doi:10.1111/j.1600-0765.2012.01489.x (2012).

54 Tsuda, H., Ochiai, K., Suzuki, N. \& Otsuka, K. Butyrate, a bacterial metabolite, induces apoptosis and autophagic cell death in gingival epithelial cells. J Periodontal Res 45, 626-634, doi:10.1111/j.1600-0765.2010.01277.x (2010).

55 Guan, X., Li, W. \& Meng, H. A double-edged sword: Role of butyrate in the oral cavity and the gut. Mol Oral Microbiol, doi:10.1111/omi.12322 (2020).

56 Fernandez, Y. M. M., Exterkate, R. A. M., Buijs, M. J., Crielaard, W. \& Zaura, E. Effect of mouthwashes on the composition and metabolic activity of oral biofilms grown in vitro. Clin Oral Investig 21, 1221-1230, doi:10.1007/s00784-016-1876-2 (2017).

57 Periasamy, S. \& Kolenbrander, P. E. Central role of the early colonizer Veillonella sp. in establishing multispecies biofilm communities with initial, middle, and late colonizers of enamel. J Bacteriol 192, 2965-2972, doi:10.1128/JB.01631-09 (2010).

58 Takahashi, N., Washio, J. \& Mayanagi, G. Metabolomics of supragingival plaque and oral bacteria. J Dent Res 89, 1383-1388, doi:10.1177/0022034510377792 (2010).

59 Magrin, G. L., Strauss, F. J., Benfatti, C. A. M., Maia, L. C. \& Gruber, R. Effects of Short-Chain Fatty Acids on Human Oral Epithelial Cells and the Potential Impact on Periodontal Disease: A Systematic Review of In Vitro Studies. Int J Mol Sci 21, doi:10.3390/ijms21144895 (2020).

60 Herrero, E. R. et al. Dysbiotic Biofilms Deregulate the Periodontal Inflammatory Response. J Dent Res 97, 547-555, doi:10.1177/0022034517752675 (2018).

61 Duran-Pinedo, A. E. et al. Community-wide transcriptome of the oral microbiome in subjects with and without periodontitis. ISME J 8, 1659-1672, doi:10.1038/ismej.2014.23 (2014).

62 Umeda, J. E., Longo, P. L., Simionato, M. R. \& Mayer, M. P. Differential transcription of virulence genes in Aggregatibacter actinomycetemcomitans serotypes. J Oral Microbiol 5, doi:10.3402/jom.v5i0.21473 (2013).

63 Hisano, K. et al. The pga gene cluster in Aggregatibacter actinomycetemcomitans is necessary for the development of natural competence in $\mathrm{Ca}(2+)$-promoted biofilms. Mol Oral Microbiol 29, 79-89, doi:10.1111/omi.12046 (2014).

64 Xie, H., Kozlova, N. \& Lamont, R. J. Porphyromonas gingivalis genes involved in fimA regulation. Infect Immun 72, 651-658, doi:10.1128/iai.72.2.651-658.2004 (2004).

65 Lee, H. R. et al. In-vivo-induced antigenic determinants of Fusobacterium nucleatum subsp. nucleatum. Mol Oral Microbiol 26, 164-172, doi:10.1111/j.20411014.2010.00594.x (2011).

66 Johansson, A., Claesson, R., Hoglund Aberg, C., Haubek, D. \& Oscarsson, J. The cagE gene sequence as a diagnostic marker to identify JP2 and non-JP2 highly leukotoxic Aggregatibacter actinomycetemcomitans serotype b strains. J Periodontal Res $5 \mathbf{2}$, 903-912, doi:10.1111/jre.12462 (2017).

67 Imamura, T. The role of gingipains in the pathogenesis of periodontal disease. $J$ Periodontol 74, 111-118, doi:10.1902/jop.2003.74.1.111 (2003). 

https://www.nature.com/srep.

\section{ACKNOWLEDGEMENTS}

\section{AUTHOR CONTRIBUTIONS}

\section{ADDITIONAL INFORMATION}

\section{Competing interests statement}

68 Bosse, J. T. et al. Regulation of pga operon expression and biofilm formation in Actinobacillus pleuropneumoniae by sigmaE and H-NS. J Bacteriol 192, 2414-2423, doi:10.1128/JB.01513-09 (2010).

69 Herrero, E. R. et al. Dysbiosis by neutralizing commensal mediated inhibition of pathobionts. Sci Rep 6, 38179, doi:10.1038/srep38179 (2016).

This study was supported by grants from the KU Leuven (Belgium) (C24/17/086) and the Research Foundation Flanders (FWO, Belgium) (FWO G091218N).

We thank loanna Chatzigiannidou (CMET, UGent) for the help with the organic acid analysis.

T.V. contributed to conception, design, data acquisition and analysis, data interpretation, drafted and critically revised the manuscript; D.V. contributed to data acquisition and analysis, data interpretation and critically revised the manuscript; W.V.H. and N.Z. contributed to data interpretation and critically revised the manuscript; K.B. and N.B. contributed to design, data interpretation and critically revised the manuscript; W.T. contributed to conception, design, data analysis and interpretation, and critically revised the manuscript.

All authors report no conflicts of interest related to this study. 

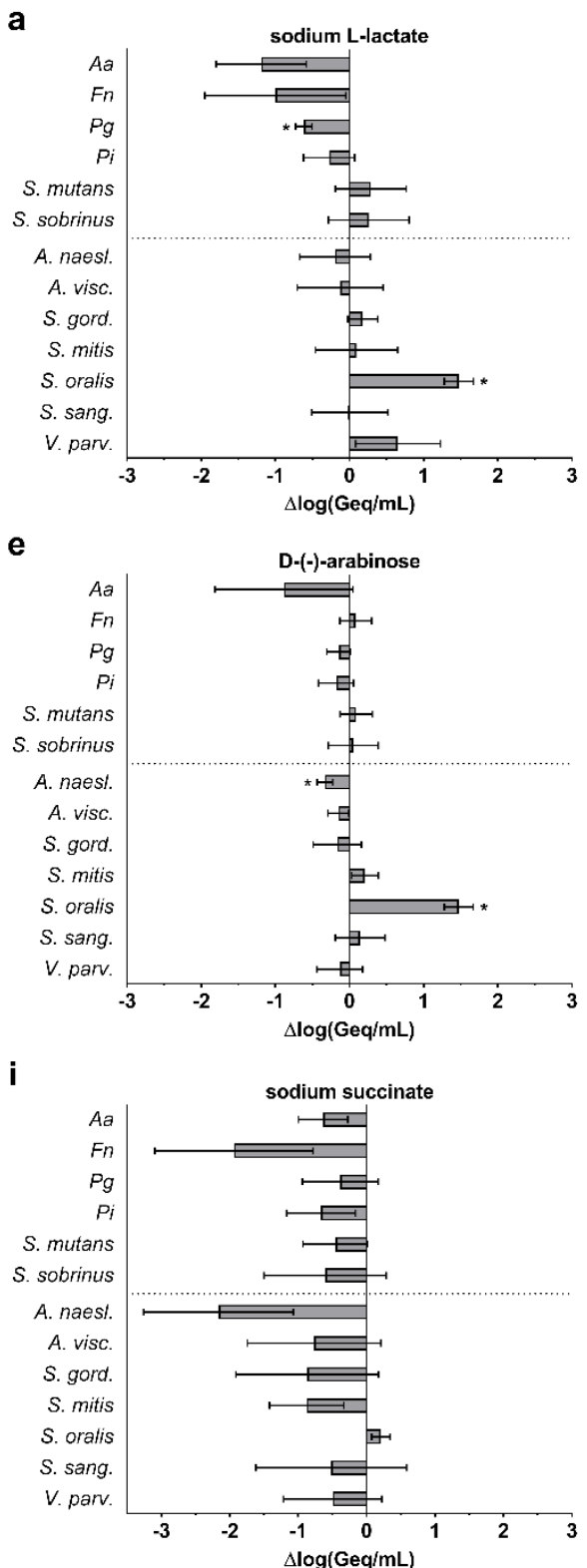
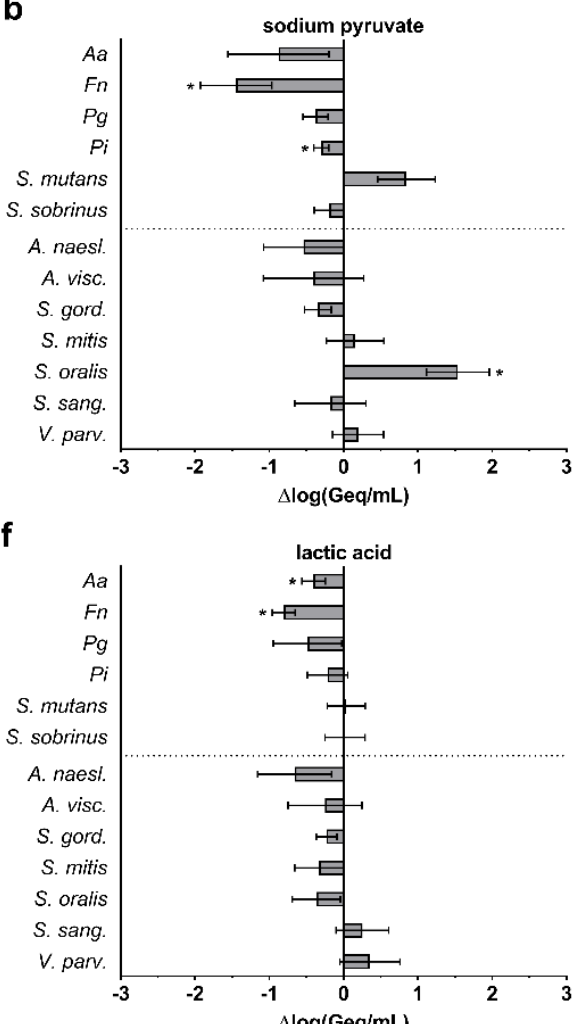

j

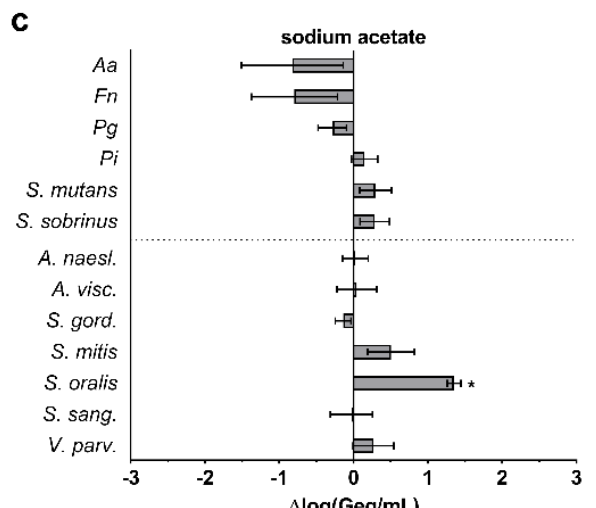

g

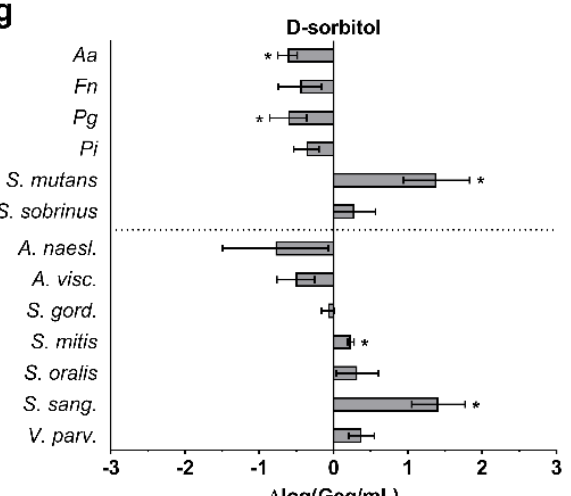

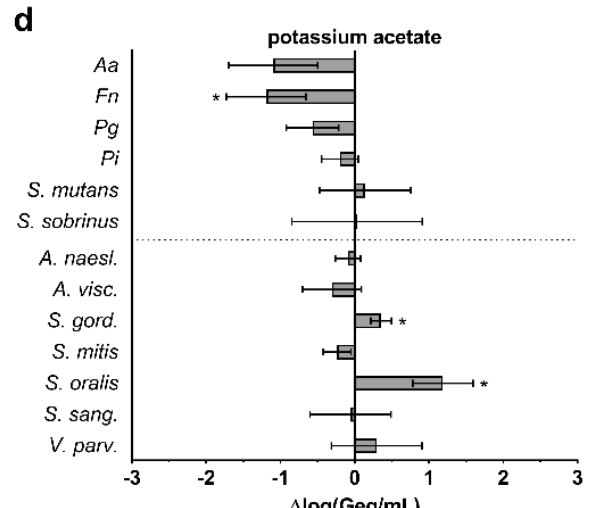

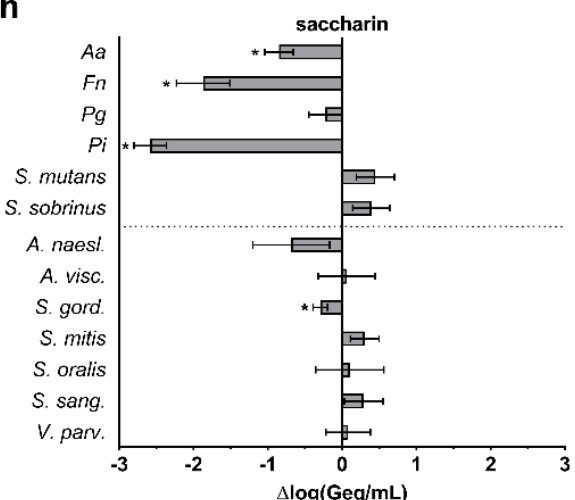

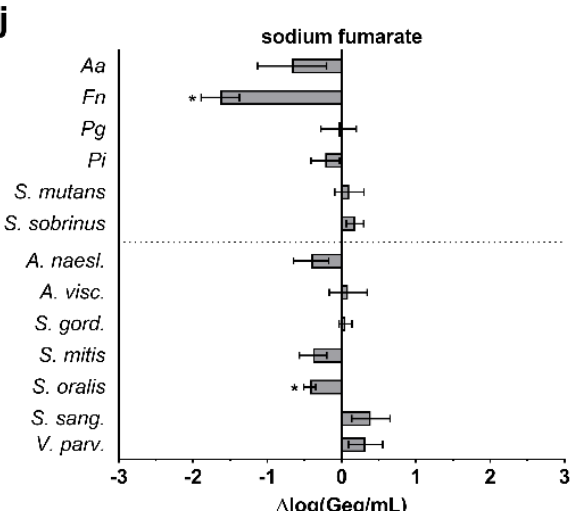

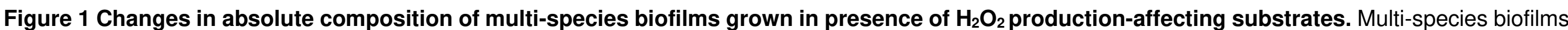

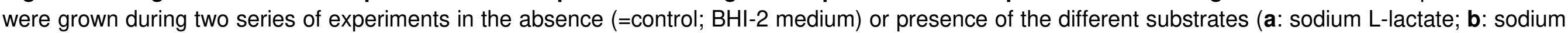


pyruvate; c: sodium acetate; $\mathbf{d}$ : potassium acetate; e: D-(-)-arabinose; $\mathbf{f}$ : lactic acid; $\mathbf{g}$ : D-sorbitol; $\mathbf{h}$ : saccharin; i: sodium succinate; $\mathbf{j}$ : sodium fumarate) dissolved in $\mathrm{BHI}-2$ medium at a concentration of $1 \%(\mathrm{w} / \mathrm{v})$. Changes in absolute abundances of each species in comparison with the control are shown as mean \pm SD $(\mathrm{n}=$ 3) and expressed in $\Delta$ logarithmic value of genome equivalents per millilitre $(\Delta \log (\mathrm{Geq} / \mathrm{mL}))$. $\Delta \log (\mathrm{Geq} / \mathrm{mL})$ was calculated by subtracting the log $(\mathrm{Geq} / \mathrm{mL})$ values of the control condition for each species from the $\log (\mathrm{Geq} / \mathrm{mL})$ values of the substrate condition for each species. $\Delta \log (\mathrm{Geq} / \mathrm{mL})$ values that are statistically significantly different from 0 (corresponding to no difference between control condition and substrate condition) are shown in bold and are marked with '*' ( $P<$ 0.05, two-tailed one sample $\mathrm{t}$ test).

Aa: A. actinomycetemcomitans; Fn: F. nucleatum; Pg: P. gingivalis; Pi: P. intermedia; A. naesl.: A. naeslundii; A. visc.: A. viscosus; S. gord.: S. gordonii; S. sang.: S. sanguinis; $V$. parv: V. parvula. 
Table 1 Changes in relative composition of multi-species biofilms grown in presence of $\mathrm{H}_{2} \mathrm{O}_{2}$ production-affecting substrates

\begin{tabular}{|c|c|c|c|}
\hline & \multicolumn{3}{|c|}{ relative abundance (\%Geq/mL) } \\
\hline & $\underline{\text { commensals }}$ & periopathogens & cariogenic pathogens \\
\hline control & $21.8 \pm 3.0$ & $77.8 \pm 3.0$ & $0.4 \pm 0.1$ \\
\hline D-sorbitol & $55.2 \pm 14.8$ * & $43.6 \pm 15.0$ * & $1.2 \pm 0.4$ \\
\hline saccharin & $82.6 \pm 8.6$ * & $13.2 \pm 6.3$ * & $4.2 \pm 2.3$ * \\
\hline lactic acid & $65.9 \pm 7.4$ * & $33.3 \pm 7.2$ * & $0.8 \pm 0.3$ \\
\hline sodium succinate & $47.5 \pm 16.6$ & $51.6 \pm 16.8$ & $0.8 \pm 0.3$ \\
\hline \multirow[t]{3}{*}{ sodium fumarate } & $74.5 \pm 7.5$ * & $24.2 \pm 7.2$ * & $1.3 \pm 0.3$ \\
\hline & \multicolumn{3}{|c|}{ relative abundance (\%Geq/mL) } \\
\hline & $\underline{\text { commensals }}$ & periopathogens & $\underline{\text { cariogenic pathogens }}$ \\
\hline control & $31.7 \pm 9.3$ & $68.3 \pm 9.3$ & $0.1 \pm 0.0$ \\
\hline sodium L-lactate & $82.9 \pm 7.0$ & $17.0 \pm 7.0$ * & $0.1 \pm 0.0$ \\
\hline sodium pyruvate & $62.4 \pm 13.6$ & $37.1 \pm 13.6$ & $0.5 \pm 0.2$ * \\
\hline D-(-)-arabinose & $33.5 \pm 19.6$ & $66.4 \pm 19.6$ & $0.1 \pm 0.0$ \\
\hline & $69.7 \pm 8.6$ & $30.2 \pm 8.6$ * & $0.1 \pm 0.1$ \\
\hline sodium acetate & $49.6 \pm 8.1$ & $50.3 \pm 8.1$ & $0.1 \pm 0.0$ \\
\hline \multicolumn{4}{|c|}{$\begin{array}{l}\text { Multi-species biofilms were grown during two series of experiments (upper part and lower part) } \\
\text { in the absence (=control; BHI- } 2 \text { medium) or presence of the different substrates dissolved in } \\
\text { BHI-2 medium at a concentration of } 1 \%(\mathrm{w} / \mathrm{v}) \text {. Relative abundances of commensals, } \\
\text { periopathogens and cariogenic pathogens are shown as mean } \pm \mathrm{SD}(\mathrm{n}=3) \text { and expressed in } \\
\% \text { genome equivalents per millilitre }(\% G e q / \mathrm{mL}) \text {. Statistically significant changes in comparison } \\
\text { with the control condition are shown in bold and are marked with '*' }(P<0.05 \text {, ANOVA + } \\
\text { Dunnett's correction for simultaneous hypothesis testing). }\end{array}$} \\
\hline
\end{tabular}


Table 2 Organic acid production/consumption by multi-species biofilms grown in presence of $\mathrm{H}_{2} \mathrm{O}_{2}$ production-affecting substrates

\begin{tabular}{|c|c|c|c|c|c|}
\hline & \multicolumn{5}{|c|}{ OA production/consumption (mg/L) } \\
\hline & lactate & formate & acetate & propionate & butyrate \\
\hline control & $-170 \pm 2$ & $94 \pm 103$ & $4312 \pm 119$ & $2722 \pm 23$ & $2498 \pm 121$ \\
\hline D-sorbitol & $-13 \pm 222$ & $383 \pm 100$ & $3889 \pm 52$ & $6726 \pm 96$ * & $1397 \pm 166$ * \\
\hline saccharin & $-194 \pm 0$ & $-78 \pm 0$ & $1549 \pm 90$ * & $1735 \pm 37$ * & $280 \pm 25$ * \\
\hline lactic acid & $85 \pm 42$ & $13 \pm 59$ & $4791 \pm 320$ & $6166 \pm 93 *$ & $1312 \pm 358$ * \\
\hline sodium succinate & $-136 \pm 8$ & $28 \pm 52$ & $3121 \pm 449$ * & $5345 \pm 54$ * & $1308 \pm 510$ * \\
\hline \multirow[t]{3}{*}{ sodium fumarate } & $1490 \pm 717^{*}$ & $114 \pm 41$ & $3864 \pm 98$ & $4557 \pm 177$ * & $409 \pm 87$ * \\
\hline & \multicolumn{5}{|c|}{ OA production/consumption (mg/L) } \\
\hline & lactate & formate & acetate & propionate & butyrate \\
\hline control & $-194 \pm 0$ & $226 \pm 7$ & $5104 \pm 105$ & $3135 \pm 182$ & $2449 \pm 224$ \\
\hline sodium L-lactate & $-104 \pm 2$ * & $203 \pm 6$ & $5907 \pm 66$ * & $7117 \pm 206$ * & $1868 \pm 117$ * \\
\hline sodium pyruvate & $-146 \pm 34$ & $921 \pm 74$ * & $7817 \pm 41$ * & $3819 \pm 40$ * & $2086 \pm 38$ * \\
\hline D-(-)-arabinose & $-134 \pm 10$ & $236 \pm 6$ & $4965 \pm 167$ & $2985 \pm 60$ & $2274 \pm 91$ \\
\hline potassium acetate & $-167 \pm 38$ & $201 \pm 4$ & $10624 \pm 14$ * & $3150 \pm 64$ & $2547 \pm 39$ \\
\hline sodium acetate & $-145 \pm 34$ & $177 \pm 13$ & $8524 \pm 264$ * & $3078 \pm 158$ & $2145 \pm 26$ \\
\hline
\end{tabular}

Multi-species biofilms were grown during two series of experiments (upper part and lower part) in the absence (=control; BHI-2 medium) or presence of the different substrates dissolved in $\mathrm{BHI}-2$ medium at a concentration of $1 \%(\mathrm{w} / \mathrm{v})$. Organic acid production/consumption (shown as mean $\pm S D(n=3)$ and expressed in $\mathrm{mg} / \mathrm{L})$ was calculated as the organic acid concentrations detected in the filter sterilized supernatants, minus the concentrations of those organic acids detected in sterile BHI-2 with or without supplemented substrate. Values preceded by a negative sign ('-") indicate organic acid consumption (net decrease), whereas all other values indicate organic acid production (net increase). Statistically significant changes in comparison with the control condition are shown in bold and are marked with '*' $(P<0.05$, ANOVA + Dunnett's correction for simultaneous hypothesis testing). OA: organic acid. 


\begin{tabular}{|c|c|c|c|c|c|c|c|c|c|c|}
\hline & \multicolumn{10}{|c|}{ relative fold change in virulence gene expression } \\
\hline & SORBI & SACCH & LA & SS & SF & SL & SP & ARA & PA & SA \\
\hline Genes & \multicolumn{10}{|c|}{ A. actinomycetemcomitans } \\
\hline apaH & $\begin{array}{c}0.28 \\
(0.04-1.84)\end{array}$ & $\begin{array}{c}0.61 \\
(0.14-2.63)\end{array}$ & $\begin{array}{c}1.39 \\
(0.47-4.17)\end{array}$ & $\begin{array}{c}1.70 \\
(0.15-18.94)\end{array}$ & $\begin{array}{c}2.56 \\
(0.33-9.85)\end{array}$ & $\begin{array}{c}1.81 \\
(0.96-3.42)\end{array}$ & $\begin{array}{c}0.73 \\
(0.7-0.76)\end{array}$ & $\begin{array}{c}0.61 \\
(0.39-0.94)\end{array}$ & $\begin{array}{c}0.84 \\
(0.36-1.97)\end{array}$ & $\begin{array}{c}2.67 \\
(0.37-19.52)\end{array}$ \\
\hline cagE & $\begin{array}{c}0.01 \\
(0.01-0.01)\end{array}$ & $\begin{array}{c}0.48 \\
(0.15-1.48)\end{array}$ & $\begin{array}{c}2.85 \\
(0.7-11.61)\end{array}$ & $\begin{array}{c}3.11 \\
(0.61-15.91)\end{array}$ & $\begin{array}{c}0.92 \\
(0.03-28.02)\end{array}$ & $\begin{array}{c}3.49 \\
(1.41-8.61)\end{array}$ & $\begin{array}{c}1.07 \\
(0.59-1.94)\end{array}$ & $\begin{array}{c}0.81 \\
(0.21-3.11)\end{array}$ & $\begin{array}{c}2.00 \\
(1.31-3.05)\end{array}$ & $\begin{array}{c}3.29 \\
(1.45-7.45)\end{array}$ \\
\hline orf859 & $\begin{array}{c}0.17 \\
(0.05-0.53)\end{array}$ & $\begin{array}{c}1.13 \\
(0.30-4.24)\end{array}$ & $\begin{array}{c}0.30 \\
(0.11-0.78)\end{array}$ & $\begin{array}{c}0.55 \\
(0.04-7.20)\end{array}$ & $\begin{array}{c}0.25 \\
(0.07-0.86)\end{array}$ & $\begin{array}{c}0.34 \\
(0.07-1.56)\end{array}$ & $\begin{array}{c}0.66 \\
(0.42-1.03)\end{array}$ & $\begin{array}{c}0.17 \\
(0.03-0.96)\end{array}$ & $\begin{array}{c}0.69 \\
(0.51-0.93)\end{array}$ & $\begin{array}{c}0.29 \\
(0.07-1.18)\end{array}$ \\
\hline$p g A$ & $\begin{array}{c}3.57 \\
(1.44-8.84)\end{array}$ & $\begin{array}{c}3.80 \\
(1.34-10.75)\end{array}$ & $\begin{array}{c}0.96 \\
(0.72-1.27)\end{array}$ & $\begin{array}{c}0.49 \\
(0.2-1.22)\end{array}$ & $\begin{array}{c}1.84 \\
(0.44-7.66)\end{array}$ & $\begin{array}{c}0.68 \\
(0.17-2.68)\end{array}$ & $\begin{array}{c}3.19 \\
(0.62-16.54)\end{array}$ & $\begin{array}{c}1.57 \\
(0.34-7.4)\end{array}$ & $\begin{array}{c}1.62 \\
(1.1-2.38)\end{array}$ & $\begin{array}{c}1.53 \\
(1.12-2.09)\end{array}$ \\
\hline Genes & \multicolumn{10}{|c|}{ F. nucleatum } \\
\hline$A B C$ tr. p. & $\begin{array}{c}0.44 \\
(0.20-0.95)\end{array}$ & $\begin{array}{c}17.98 \\
(13.4-24.2)\end{array}$ & $\begin{array}{c}0.45 \\
(0.16-1.26)\end{array}$ & $\begin{array}{c}3.96 \\
(1.15-13.67)\end{array}$ & $\begin{array}{c}4.98 \\
(3.51-7.06)\end{array}$ & $\begin{array}{c}3.71 \\
(2.66-5.19)\end{array}$ & $\begin{array}{c}2.29 \\
(0.85-6.16)\end{array}$ & $\begin{array}{c}1.16 \\
(0.80-1.70)\end{array}$ & $\begin{array}{c}3.49 \\
(1.60-7.59)\end{array}$ & $\begin{array}{c}3.96 \\
(1.59-9.91)\end{array}$ \\
\hline $\begin{array}{l}\text { hemin } \\
\text { rec. }\end{array}$ & $\begin{array}{c}0.11 \\
(0.02-0.53)\end{array}$ & $\begin{array}{c}3.05 \\
(0.67-13.99)\end{array}$ & $\begin{array}{c}0.15 \\
(0.03-0.75)\end{array}$ & $\begin{array}{c}0.42 \\
(0.11-1.62)\end{array}$ & $\begin{array}{c}0.51 \\
(0.17-1.50)\end{array}$ & $\begin{array}{c}1.15 \\
(0.35-3.82)\end{array}$ & $\begin{array}{c}0.33 \\
(0.02-4.28)\end{array}$ & $\begin{array}{c}0.39 \\
(0.07-2.30)\end{array}$ & $\begin{array}{c}0.43 \\
(0.09-1.96)\end{array}$ & $\begin{array}{c}0.29 \\
(0.15-0.58)\end{array}$ \\
\hline hemolysin & $\begin{array}{c}1.08 \\
(0.48-2.44)\end{array}$ & $\begin{array}{c}3.60 \\
(2.02-6.41)\end{array}$ & $\begin{array}{c}0.72 \\
(0.31-1.66)\end{array}$ & $\begin{array}{c}1.63 \\
(0.38-7.04)\end{array}$ & $\begin{array}{c}0.66 \\
(0.24-1.85)\end{array}$ & $\begin{array}{c}1.27 \\
(0.53-3.03)\end{array}$ & $\begin{array}{c}1.15 \\
(0.17-7.79)\end{array}$ & $\begin{array}{c}0.99 \\
(0.51-1.92)\end{array}$ & $\begin{array}{c}1.58 \\
(1.31-1.92)\end{array}$ & $\begin{array}{c}1.03 \\
(0.36-2.96)\end{array}$ \\
\hline Genes & \multicolumn{10}{|c|}{ P. gingivalis } \\
\hline $\operatorname{fim} A$ & $\begin{array}{c}1.56 \\
(0.18-13.18)\end{array}$ & $\begin{array}{c}3.58 \\
(2.07-6.18)\end{array}$ & $\begin{array}{c}0.61 \\
(0.23-1.60)\end{array}$ & $\begin{array}{c}0.30 \\
(0.13-0.71)\end{array}$ & $\begin{array}{c}0.42 \\
(0.13-1.39)\end{array}$ & $\begin{array}{c}0.28 \\
(0.13-0.60)\end{array}$ & $\begin{array}{c}1.46 \\
(0.26-8.20)\end{array}$ & $\begin{array}{c}0.60 \\
(0.17-2.14)\end{array}$ & $\begin{array}{c}2.71 \\
(1.35-5.45)\end{array}$ & $\begin{array}{c}0.46 \\
(0.13-1.67)\end{array}$ \\
\hline kgp & $\begin{array}{c}0.45 \\
(0.07-2.89)\end{array}$ & $\begin{array}{c}0.04 \\
(0.01-0.18)\end{array}$ & $\begin{array}{c}2.33 \\
(1.76-3.08)\end{array}$ & $\begin{array}{c}1.43 \\
(0.23-8.90)\end{array}$ & $\begin{array}{c}0.41 \\
(0.36-0.46)\end{array}$ & $\begin{array}{c}1.31 \\
(0.3-5.74)\end{array}$ & $\begin{array}{c}18.79 \\
(7.13-49.53)\end{array}$ & $\begin{array}{c}2.20 \\
(0.24-19.88)\end{array}$ & $\begin{array}{c}3.68 \\
(1.75-7.76)\end{array}$ & $\begin{array}{c}1.23 \\
(0.3-5.08)\end{array}$ \\
\hline $\operatorname{rgp} A$ & $\begin{array}{c}1.01 \\
(0.6-1.72)\end{array}$ & $\begin{array}{c}0.40 \\
(0.12-1.41)\end{array}$ & $\begin{array}{c}0.58 \\
(0.13-2.58)\end{array}$ & $\begin{array}{c}0.28 \\
(0.04-2.10)\end{array}$ & $\begin{array}{c}0.32 \\
(0.29-0.35)\end{array}$ & $\begin{array}{c}0.21 \\
(0.06-0.72)\end{array}$ & $\begin{array}{c}0.73 \\
(0.22-2.41)\end{array}$ & $\begin{array}{c}0.61 \\
(0.14-2.58)\end{array}$ & $\begin{array}{c}1.80 \\
(0.49-6.63)\end{array}$ & $\begin{array}{c}0.25 \\
(0.02-3.20)\end{array}$ \\
\hline
\end{tabular}

relative fold change values

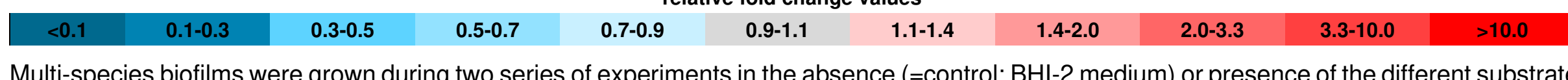
dissolved in $\mathrm{BH}-2$ medium at a concentration of $1 \%(\mathrm{w} / \mathrm{v})$. Changes in the expression of a selection of virulence genes from three periodontal pathogens present in the multi-species biofilms were determined. Fold changes in virulence gene expression were calculated with the $2^{\wedge-\Delta \Delta C t}$ method and were determined relative to the control $(\mathrm{BHI}-2)$. Data are shown as geometric mean and $\mathrm{C} . \mathrm{I}$. $(\mathrm{n}=3)$ of the $2^{\wedge-\Delta \Delta \mathrm{Ct}}$ values. Values between 0 and 1 indicate downregulation relative to the control, values $>1$ indicate upregulation relative to the control. Statistically significantly different fold changes relative to the control with a value $<0.5$ (more than 2-fold downregulated) or $>1.5$ (more than 1.5 -fold upregulated) are considered biologically relevant and are shown in bold $(P<0.05$, ANOVA + Dunnett's correction for simultaneous hypothesis testing). The color 
scale indicates the magnitude of the fold change in virulence gene expression relative to the control. SORBI: D-sorbitol; SACCH: saccharin; LA: lactic acid; SS: sodium succinate; SF: sodium fumarate; SL: sodium L-lactate; SP: sodium pyruvate; ARA: D-(-)-arabinose; PA: potassium acetate; SA: sodium acetate; ABC tr. p.: ABC transporter permease; hemin rec.: hemin receptor; C.I.: 95\% confidence interval. 


\section{Figures}

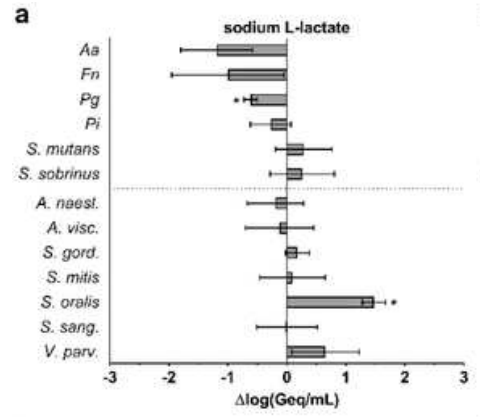

e
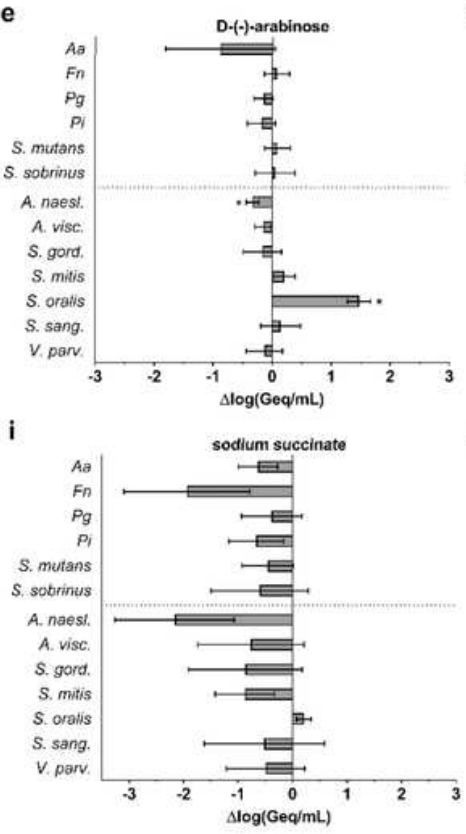

b

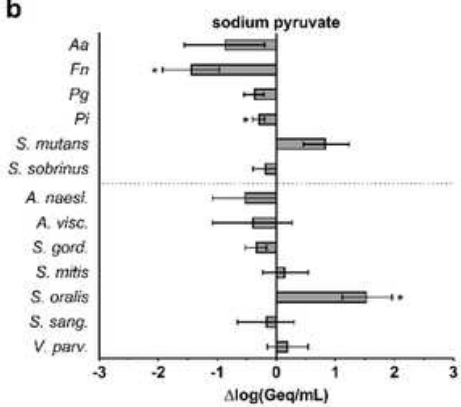

f

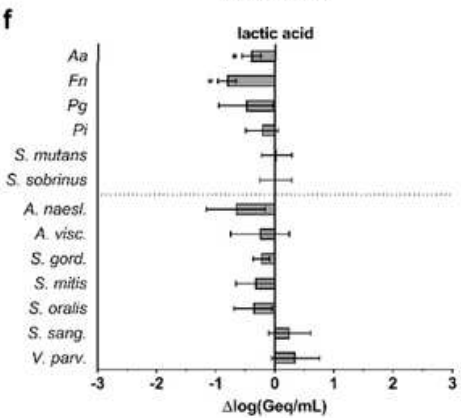

j

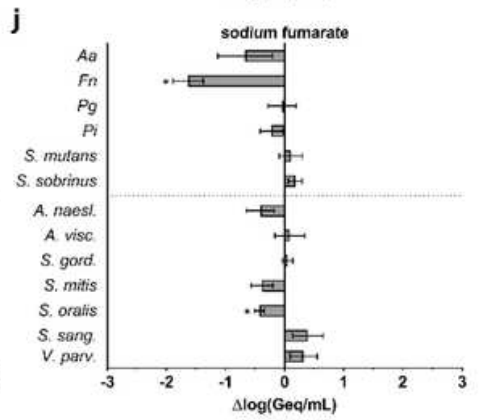

c

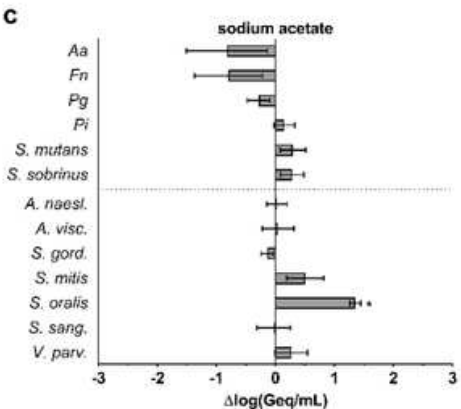

g

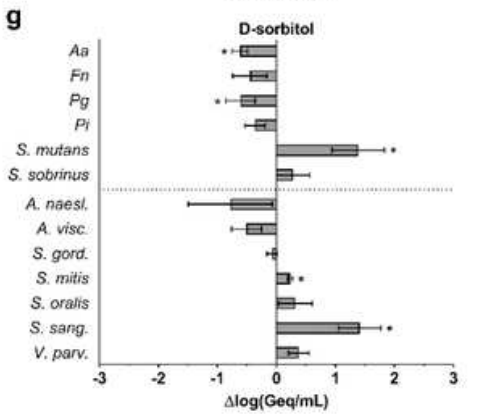

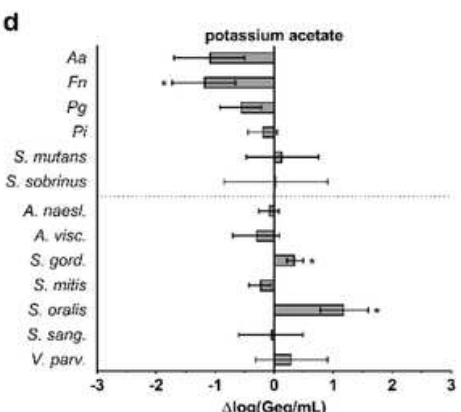

h

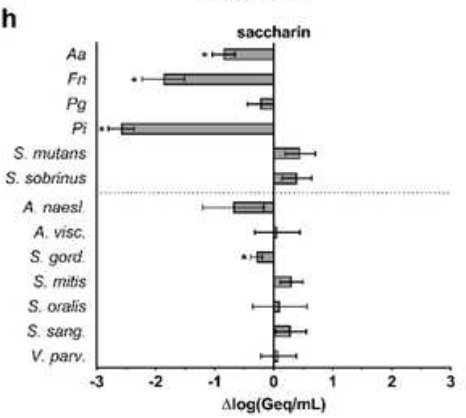

\section{Figure 1}

Changes in absolute composition of multi-species biofilms grown in presence of $\mathrm{H} 2 \mathrm{O} 2$ productionaffecting substrates. Multi-species biofilms were grown during two series of experiments in the absence (=control; BHI-2 medium) or presence of the different substrates (a: sodium L-lactate; b: sodium pyruvate; c: sodium acetate; d: potassium acetate; e: D-(-)-arabinose; f: lactic acid; g: D-sorbitol; h: saccharin; i: sodium succinate; $\mathrm{j}$ : sodium fumarate) dissolved in BHI-2 medium at a concentration of $1 \%(\mathrm{w} / \mathrm{v})$. Changes in absolute abundances of each species in comparison with the control are shown as mean \pm $S D(n=3)$ and expressed in $\Delta$ logarithmic value of genome equivalents per millilitre $(\Delta \log (\mathrm{Geq} / \mathrm{mL}))$. $\Delta \log (\mathrm{Geq} / \mathrm{mL})$ was calculated by subtracting the $\log (\mathrm{Geq} / \mathrm{mL})$ values of the control condition for each species from the $\log (\mathrm{Geq} / \mathrm{mL})$ values of the substrate condition for each species. $\Delta \log (\mathrm{Geq} / \mathrm{mL})$ values that are statistically significantly different from 0 (corresponding to no difference between control condition and substrate condition) are shown in bold and are marked with ' $*$ ' $(P<0.05$, two-tailed one sample t test). Aa: A. actinomycetemcomitans; Fn: F. nucleatum; Pg: P. gingivalis; Pi: P. intermedia; A. naesl.: A. naeslundii; A. visc.: A. viscosus; S. gord.: S. gordonii; S. sang.: S. sanguinis; V. parv: V. parvula. 


\section{Supplementary Files}

This is a list of supplementary files associated with this preprint. Click to download.

- Supplementaryinformation.pdf 